\title{
Perioperative immune responses in cancer patients undergoing digestive surgeries
}

\author{
Masashi Ishikawa*1, Masanori Nishioka², Norikazu Hanaki², \\ Takayuki Miyauchi ${ }^{2}$, Yutaka Kashiwagi ${ }^{2}$, Hiromi Ioki ${ }^{2}$, Akihiro Kagawa ${ }^{2}$ and \\ Yoichi Nakamura ${ }^{2}$
}

\author{
Address: ${ }^{1}$ Department of Surgery, Tokushima Red Cross hospital103 Irinokuchi, Komatsushima city, Tokushima, Japan and ${ }^{2}$ Department of \\ Surgery, National Kochi Hospital, Japan \\ Email: Masashi Ishikawa* - masa1192@tokushima-med.jrc.or.jp; Masanori Nishioka - masa1192@tokushima-med.jrc.or.jp; \\ Norikazu Hanaki - masa1192@tokushima-med.jrc.or.jp; Takayuki Miyauchi - masa1192@tokushima-med.jrc.or.jp; \\ Yutaka Kashiwagi - masa1192@tokushima-med.jrc.or.jp; Hiromi Ioki - masa1192@tokushima-med.jrc.or.jp; \\ Akihiro Kagawa - masa1192@tokushima-med.jrc.or.jp; Yoichi Nakamura - masa1192@tokushima-med.jrc.or.jp \\ * Corresponding author
}

Published: 12 January 2009

World Journal of Surgical Oncology 2009, 7:7 doi:10.1 | 86/1477-78|9-7-7

This article is available from: http://www.wjso.com/content/7///7

(C) 2009 Ishikawa et al; licensee BioMed Central Ltd.

This is an Open Access article distributed under the terms of the Creative Commons Attribution License (http://creativecommons.org/licenses/by/2.0), which permits unrestricted use, distribution, and reproduction in any medium, provided the original work is properly cited.
Received: 26 October 2008

Accepted: 12 january 2009

\begin{abstract}
Background: Th1/Th2 cell balance is thought to be shifted toward a Th2-type immune response not only by malignancy but also by surgical stress. The aim of this study was to estimate perioperative immune responses with respect to the Thl/Th2 balance in patients with gastrointestinal cancer.
\end{abstract}

Methods: Ninety-four patients who underwent abdominal surgeries were divided into three groups: gastric resection $(n=40)$, colorectal resection $(n=34)$ and hepatic resection $(n=20)$. Twelve patients undergoing laparoscopic cholecystectomy and 20 healthy subjects were served as control groups. Intracellular cytokine staining in CD4+ T lymphocytes was identified to characterize ThI/Th2 balance. Thl/Th2 balance was evaluated before operation and until postoperative days (POD) 14.

Results: The preoperative ThI/Th2 ratio was significantly lower in patients with malignancy compared with control. The ThI/Th2 ratio of patients in all groups decreased significantly postoperatively. Th I/Th2 balance on POD 2 in patients with malignancy was significantly decreased compared to patients with laparoscopic cholecystectomy, but there were no significant differences among the four groups on POD 14.

Conclusion: Patients with malignancy showed an abnormal perioperative ThI/Th2 balance suggesting predominance of a type- 2 immune response. Major abdominal surgeries induce a marked shift in Th1/Th2 balance toward Th2 in the early postoperative stage.

\section{Background}

Immunity to malignancy is influenced not only by CD8+ $\mathrm{T}$ cells, but also by the function of $\mathrm{CD} 4+\mathrm{T}$ helper $(\mathrm{Th})$ lymphocytes, which are important in cell-mediated and humoral immunity [1]. Since the initial description by Mosmann et al. [2] of subclasses of CD4+ helper T cells 
(Th) that differ in cytokine secretion, immune responses have been classified into type 1 responses that provide cell-mediated immunity, and type 2 responses that support $\mathrm{B}$ cell functions and the humoral immune response. Exposure of naïve Th cells to certain antigens and cytokines causes CD4+ T cells to assume one of these two distinct phenotypes. Th1 cells produce predominantly interferon- $\gamma($ IFN- $\gamma$ ) and interleukin-2 (IL-2), whereas Th2 cells secrete predominantly IL-4, IL-6 and IL-10 [3].

Several studies have shown reduced secretion of Th1 in bulk cultures of peripheral blood mononuclear cells (PBMC) from advanced cancer patients $[4,5]$. However, a few studies of Th1/Th2 balance have been performed on large numbers of patients with abdominal cancer $[6,7]$. The first objective of the present study was to estimate roles of these two CD4+ subsets in anti-tumor immunity.

It has been reported that the Th1/Th2 cell balance is shifted toward a Th2-type immune response not only by malignancy but also by surgical stress [8-10]. Decker et al. [11] have shown that surgical stress induces a shift in the Th1/Th2 cell balance, suggesting a down-regulation of cell-mediated and up-regulation of antibody-mediated immunity commensurate with surgical trauma. However, the extent to which surgical stress influences the Th1/Th2 balance is unknown. The second objective of this study was to assess changes in the Th1/Th2 balance in patients undergoing surgical stress, and to clarify whether a shift in the Th1/Th2 balance can be used to facilitate comparisons of different abdominal surgeries.

\section{Patients and methods}

Ninety-four consecutive patients (55 males, 39 females; mean age of $66 \pm 11$ years) underwent abdominal surgery for the first time at our clinic between April 2000 and April 2002. The experimental protocol was approved by the Research Committee of National Kochi Hospital. All patients were informed of the nature and risk of this study, and written informed consent was obtained. The criteria for inclusion were major surgical tumor resection (digestive tract or liver cancers) and expected duration of operation of 3 hours or more. The patients were divided into the following three groups according to surgical pro- cedure. Forty gastric resections for gastric cancer (24 males, 16 females; mean age of $65 \pm 13$ years), 34 colorectal resections for colorectal cancer (19 males, 15 females; mean age of $66 \pm 15$ years) and 20 hepatic resection for liver cancer ( 8 hepatocellular carcinomas, 5 liver metastases and 7 biliary tract carcinomas) ( 12 males, 8 females; mean age of $66 \pm 8$ years) were performed, respectively (Table 1).

Twelve laparoscopic cholecystectomy (LC) (6 males, 6 females; mean age of $58 \pm 14$ years) and 20 healthy subjects ( 10 males and 10 females; mean age of $60 \pm 12$ years) served as the control groups. The patients with malignancy were divided into four groups corresponding to the four stages of disease (stage I $(n=28)$, stage II $(n=36)$, stage III $(n=22)$, stage IV ( $n=8)$, respectively) by UICC classification. The duration of operation and operative blood loss for each procedure were $223 \pm 55 \mathrm{~min}$ and 267 $\pm 212 \mathrm{ml}$ for gastric resection, $220 \pm 71 \mathrm{~min}$ and $325 \pm 336$ $\mathrm{ml}$ for colorectal resection, $365 \pm 85 \mathrm{~min}$ and $761 \pm 759$ $\mathrm{ml}$ for hepatic resection and $116 \pm 45 \mathrm{~min}$ and $46 \pm 80 \mathrm{ml}$ for LC, respectively. Ten patients (5 [25\%] hepatic resections, $2[5 \%]$ gastric resections, $3[9 \%]$ colorectal resections) developed postoperative complications (4 abdominal abscesses, 4 leakages and 2 pneumonia). These major infectious complications typically occurred on POD 4 or 5 (range 3-7 days). All patients had a relatively uneventful recovery within POD 30 (range 15-25 days). No patients with laparoscopic cholecystectomy developed postoperative complications.

\section{Flow cytometric analysis of intracellular IFN- $\gamma$ and IL-4}

Blood sampling was performed before surgery, and on POD 2 and 14. CBC and leukocyte differential analyses were performed with an automated cell counter (Sysmex SE-9000, Kobe, Japan). The proportion of CD4+ lymphocytes producing IFN- $\gamma$, IL-2, IL-4 and IL- 6 were measured by flow cytometry (Beckman Coulter, Inc., Florida, Miami, USA) as described by Openshaw et al, [12] Briefly, $1 \mathrm{ml}$ of each blood sample was treated immediately with $10 \mathrm{ng} / \mathrm{ml}$ of Brefeldin A (Sigma B7651), kept at ambient temperature, and prepared within 2 hours. Peripheral blood lymphocytes were harvested, washed, and resuspended at $10^{5}-10^{6} / \mathrm{ml}$ and stimulated with PMA

Table I: Details of the procedures

\begin{tabular}{lccccc}
\hline Disease & Case & Male:female & Surgical procedure & Operating time (min) & Intraoperative bleeding (ml) \\
\hline Gastric cancer & 40 & $24: 16$ & Gastric resection (40) & $223 \pm 55$ & $267 \pm 212$ \\
Colon cancer & 34 & $19: 15$ & Intestinal resection (34) & $220 \pm 71$ & $325 \pm 336$ \\
Hepatobiliary cancer & 20 & $12: 8$ & Partial resection (8) & $365 \pm 85$ & $761 \pm 759$ \\
HCC & 8 & $12: 8$ & Subsegmental resection (2) & $365 \pm 85$ & $761 \pm 759$ \\
Liver metastasis & 5 & $12: 8$ & Segmental resection (3) & $365 \pm 85$ & $761 \pm 759$ \\
Ca of biliary tract & 7 & $12: 8$ & Lobectomy (7) & $365 \pm 85$ & $761 \pm 759$ \\
Cholelithiasis & 12 & $6: 6$ & Laparoscopic cholecystectomy (12) & $116 \pm 45$ & $46 \pm 180$
\end{tabular}


50 ng/ml (Sigma P8139) plus ionomycin (Sigma 10634) $500 \mathrm{ng} / \mathrm{ml}$. After a wash and 10-min incubation in PBS/ $\mathrm{BSA} /$ saponin, cells were incubated with anti-CD4 monoclonal Ab and anti-IFN- $\gamma$ (DAKO, RG285, Denmark), anti-IL-2 (DAKO, RG202), anti-IL-4 (DAKO, RG204) or anti-IL-6 (DAKO, RG206) for 30 min before adding an equal volume of $4 \%$ formaldehyde fixative. After washing and incubating with PBS/BSA/saponin for $10 \mathrm{~min}$, cells were incubated with for $30 \mathrm{~min}$, respectively. Results were analyzed using the XL/XL-MCL system and were calculated as a ratio of the percent IFN- $\gamma$-producing (Th1) cells to IL-4-producing (Th2) cells.

\section{Statistical analysis}

Values for results are presented as means \pm SD. Student's $t$ test was used for comparison of continuous variables. Differences between groups with respect to time were compared using the analysis of variance (ANOVA) for repeated measures. A p value of $<0.05$ was considered significant.

\section{Results}

The lymphocyte count in all patients decreased significantly after surgery, reaching a nadir of almost one-third of baseline on POD 2 (Fig. 1). There was no significant difference in the lymphocyte count among the four groups including the LC group before surgery. Patients with hepatic resection presented with $531 \pm 24$ cells $/ \mu$ on POD 2, then rebounded by POD 14 to $1017 \pm 494$ cells/ $\mu \mathrm{l}$. However, the lymphocyte count in patients with hepatic resection was significantly lower than in those with gastric and colorectal resection on POD 2 and 14 .

The preoperative percentage of IL-4-producing $\mathrm{T}$ cells from PBMC of patients with malignancy was significantly higher than in the control groups, while patients who underwent LC showed no significant differences from the healthy controls. In contrast, the preoperative percentages of IL-2, IFN- $\gamma$ and IL-6-producing T cells in all patient groups were similar to the healthy control group. Therefore, the preoperative ratio of the percentage of IFN-g-pro-

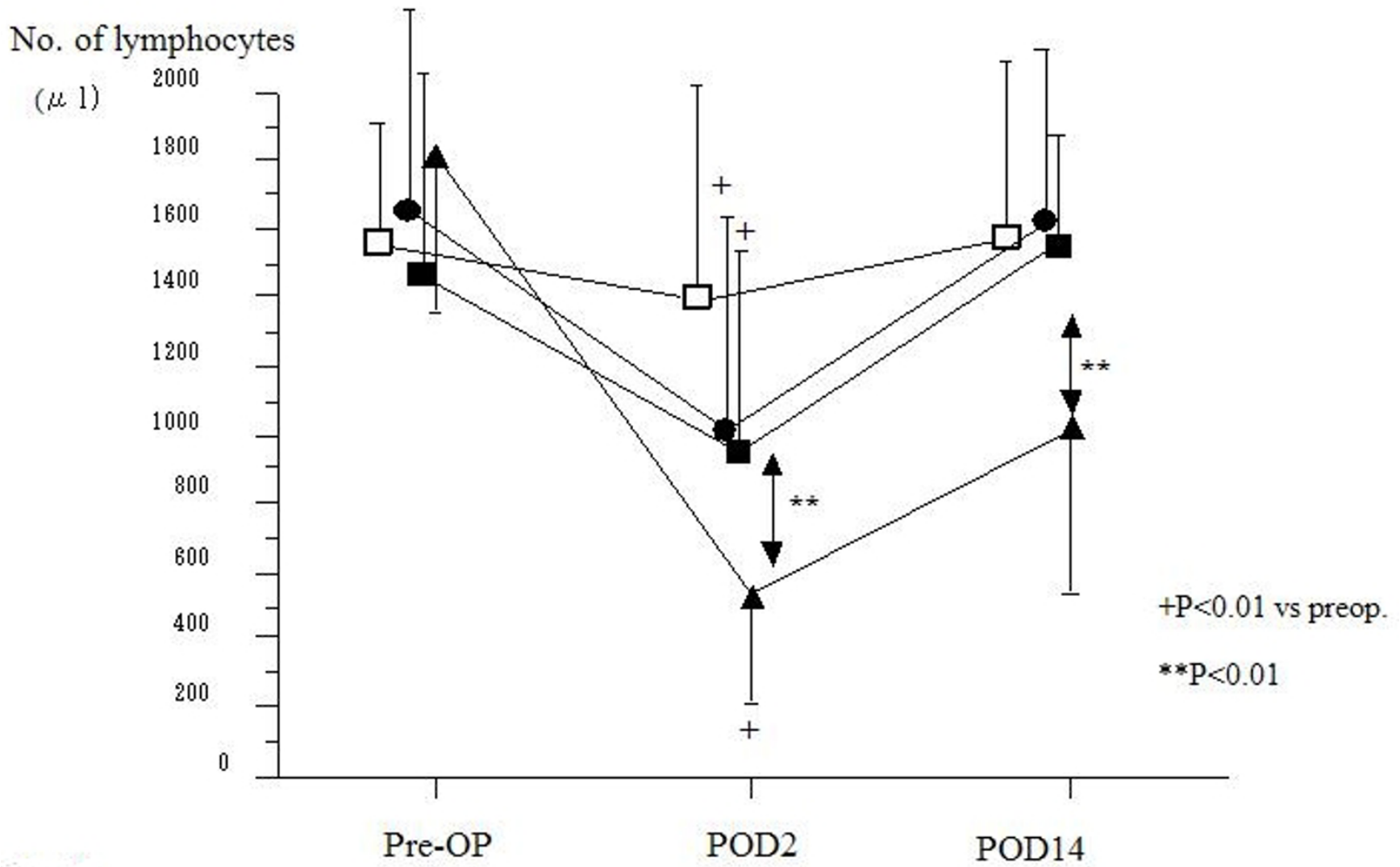

\section{Figure I}

Lymphocyte counts for patients. (Black squares - gastric resection $(n=40)$, black circles - colorectal resection $(n=34)$, black triangles - hepatic resection $(n=20)$, white squares - laparoscopic cholecystectomy $(n=12)$ ). Lymphocyte count in all groups decreased significantly after surgery. The lymphocyte counts for patients with hepatic resection became significantly lower than those in the gastric and colorectal resection groups after surgery. 
ducing T cells (Th1) to IL-4-producing T cells (Th2) was significantly higher in healthy controls and patients who underwent LC than in those who underwent operations for malignancy, the means being $11.3 \pm 4.3$, $10.8 \pm 5.6$ and $6.8 \pm 4.2(\mathrm{p}<0.01)$, respectively. There were no significant differences in the preoperative ratio of Th1 to Th2 among gastric, colorectal and hepatic resection groups, the mean being $5.2 \pm 3.6$ in patients with gastric cancer, $7.2 \pm 3.1$ in those with colorectal cancer and $6.6 \pm 4.0$ in those with hepatic cancer (Fig. 2). Preoperatively, malignancy groups showed a significantly higher percentage of T cells producing IL- 4 than that of LC and healthy control groups. Interestingly, no significant differences were observed according to staging in patients with malignant disease: $6.9 \pm 3.5$ in stage I, $6.5 \pm 3.7$ in stage II, $6.6 \pm 3.1$ in stage III, $5.5 \pm 2.6$ in stage IV.

Postoperatively, the ratio of Th1 to Th2 decreased in all groups $(4.5 \pm 3.0$ in malignancy groups, $6.7 \pm 4.1$ in LC groups on POD 2) (Fig. 2). The ratio of Th $1 / 2$ in patients with malignancy markedly decreased to $4.3 \pm 2.1$ in gastric resection, $4.9 \pm 2.6$ in colorectal resection and $2.9 \pm$ 1.6 in hepatic resection on POD 2, with significant differences $(\mathrm{p}<0.05)$ compared to patients undergoing LC.
However, these ratios recovered to preoperative levels on POD 14 in all groups. There were no significant differences in the percentage of CD $4+\mathrm{IFN}-\gamma+\mathrm{T}$ cells among all groups prior to surgery $(14.0 \pm 8.5 \%$ in gastric resection, $13.6 \pm 6.6 \%$ in colorectal resection, $16.3 \pm 8.3 \%$ in hepatic resection and $14.6 \pm 15.6 \%$ in LC). Significant changes in the postoperative percentage of $\mathrm{CD} 4+\mathrm{IFN} \gamma+\mathrm{T}$ cells were not seen other than a reduction on POD 2 in the hepatic resection group $(11.7 \pm 6.9 \%, \mathrm{P}<0.05)$ (Fig. 3$)$. In contrast to CD $4+\mathrm{IFN} \gamma+\mathrm{T}$ cells frequencies, the percentage of CD4+IL-4+ T cells in all groups significantly increased on POD $2(5.1 \pm 2.7 \%$ in gastric resection, $4.5 \pm 2.7 \%$ in colorectal resection, $5.5 \pm 2.8 \%$ in hepatic resection and $3.2 \pm 3.0 \%$ in LC) compared with before surgery $(4.1 \pm$ $2.5 \%$ in gastric resection, $2.6 \pm 1.5 \%$ in colorectal resection, $3.3 \pm 2.6 \%$ in hepatic resection and $1.6 \pm 1.3 \%$ in LC) (Fig. 4).

There were no significant differences in the percentage of CD4+IL-2+ T cells among all groups prior to surgery (17.2 $\pm 16.6 \%$ in gastric resection, $12.7 \pm 11.0 \%$ in colorectal resection, $16.2 \pm 12.7 \%$ in hepatic resection and $8.0 \pm$ $5.8 \%$ in LC). No significant differences in the percentage of CD4+IL-2+ T cells among all groups after surgery were

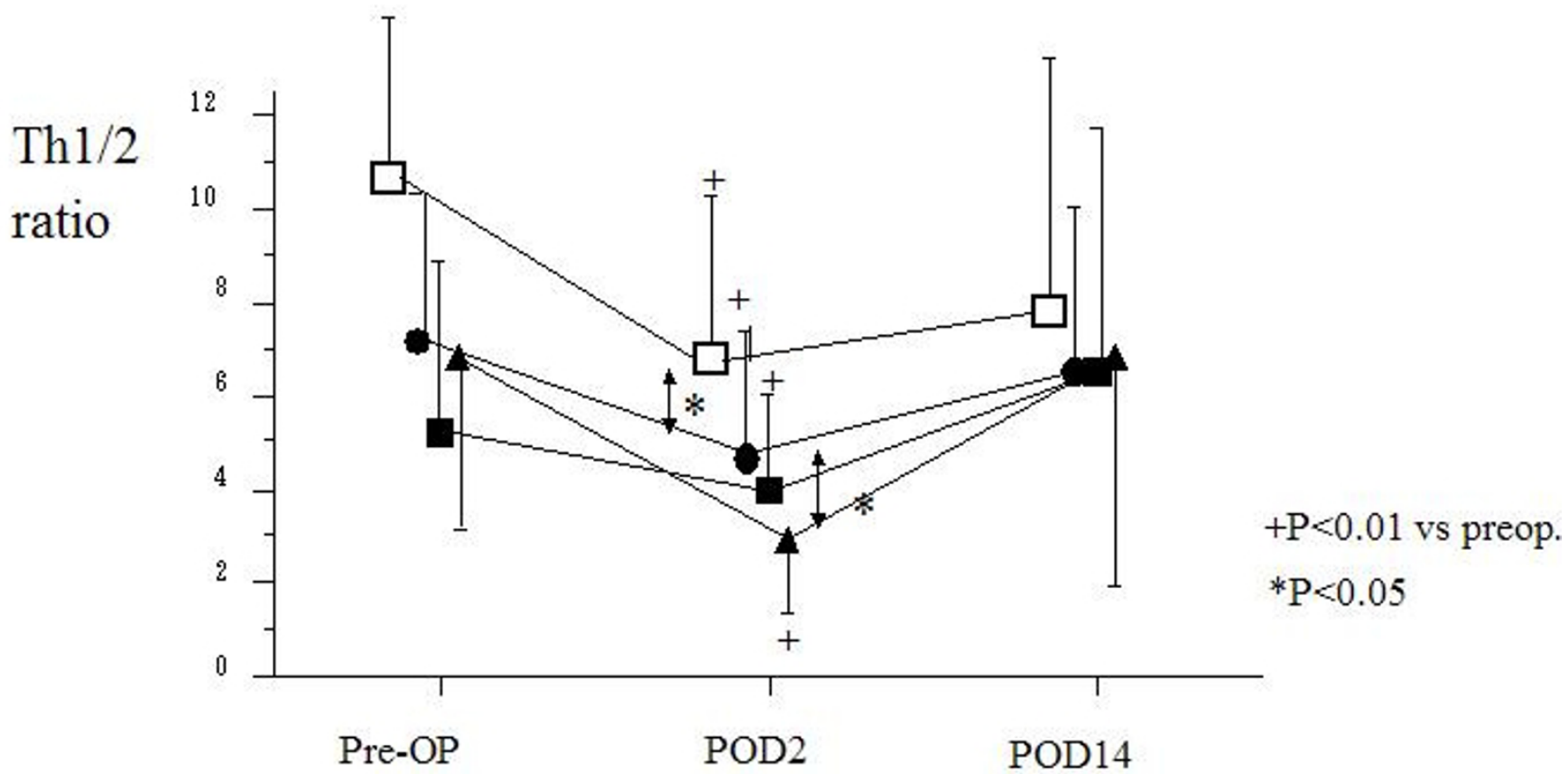

\section{Figure 2}

Changes in the Th $\mathrm{I} / 2$ ratio in surgical patients with respect to operative procedure. (Black squares - gastric resection $(n=40)$, black circles - colorectal resection $(n=34)$, black triangles - hepatic resection $(n=20)$, white squares - laparoscopic cholecystectomy $(\mathrm{n}=12))$. The ThI/2 ratio in all groups decreased significantly on POD 2 and significant differences were noted between malignancy group and LC group. However, the ratio in all groups recovered to preoperative levels on POD 14. 


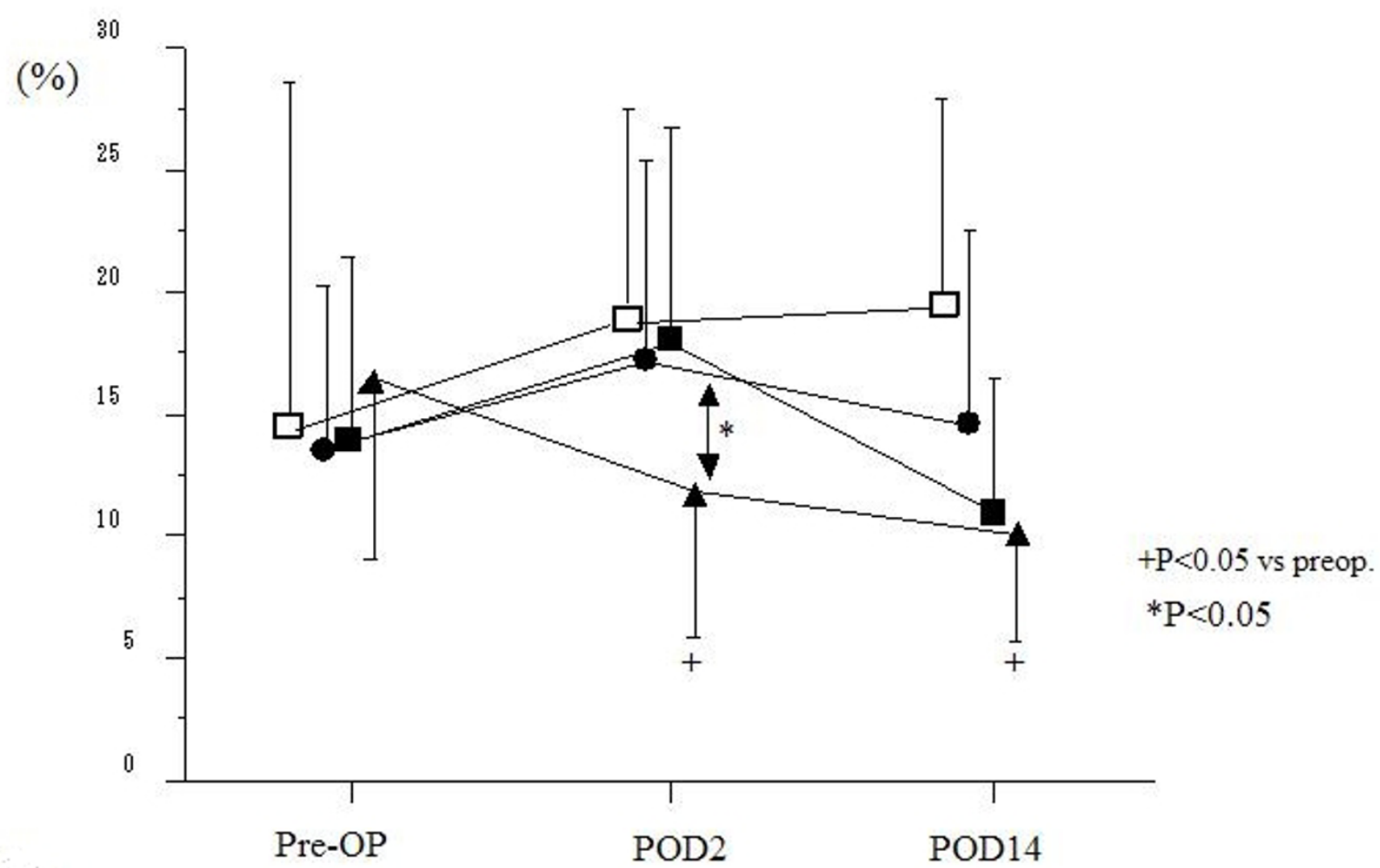

\section{Figure 3}

Perioperative changes of measurements of IFN- $\gamma$ in surgical patients. (Black squares - gastric resection $(n=40)$, black circles - colorectal resection $(n=34)$, black triangles - hepatic resection $(n=20)$, white squares - laparoscopic cholecystectomy $(\mathrm{n}=12)$ ). There were no significant differences in the percentage of CD4+ IFN $-\gamma+T$ cells among all groups prior to surgery. Significant decrease, however, in the postoperative percentage of CD4+ IFN- $\gamma+\mathrm{T}$ cells were not seen other than the reduction on POD 2 in the hepatic resection group.

found. On the other hand, there were also no significant differences in the percentage of CD4+IL- $6+$ T cells among all groups prior to surgery $(39.2 \pm 28.9 \%$ in gastric resection, $32.1 \pm 23.3 \%$ in colorectal resection, $40.0 \pm 24.9 \%$ in hepatic resection and $30.3 \pm 37.0 \%$ in LC), showing no significant differences among all groups after surgery.

In the malignancy group there were no significant differences between patients with and without postoperative complications prior to surgery and on POD $2(4.6 \pm 2.5 v s$. $4.4 \pm 3.2)$, but the Th1/2 ratio in 10 patients with postoperative complications was $3.5 \pm 2.0$ on POD 14 , significantly lower than in patients without postoperative complications $(7.2 \pm 4.4, \mathrm{p}<0.05)$ (Fig. 5). The percentages of $\mathrm{CD} 4+\mathrm{IFN}-\gamma+\mathrm{T}$ cells in patients with postoperative complications decreased significantly to $11.4 \pm 6.1 \%$ on POD 14 compared to patients without postoperative complications $(14.6 \pm 6.6 \%)$. In contrast, the percentage of CD4+ IL-4+ T cells in patients with and without complications on POD 2 exhibited the opposite trend $(5.3 \pm 1.5$ vs.
$4.3 \pm 1.0 \%$, for patients with and without complications, respectively, $\mathrm{p}<0.05)$.

\section{Discussion}

Some previous studies have shown that cell-mediated but not humoral immunity is impaired in cancer patients [13]. However, it has not been determined whether this impairment is more generally associated with the presence tumors. Surprisingly, among patients with cancer in the present study, there were no differences in the Th1/ Th2 ratio between the patients with early cancer and advanced cancer. It therefore seems that, in advanced cancer patients, the shift towards Th2 might be due to altered representation of subsets as well as a change in capacity of cells to secrete cytokine. However, Pellegrini et al. [4] reported that serum levels of IL-4 in patients with stage I disease were significantly higher than control subjects and positively correlated with disease stage. Therefore, they also examined cytokine produced by tumor-draining lymphocytes from lymph nodes and reported that when 


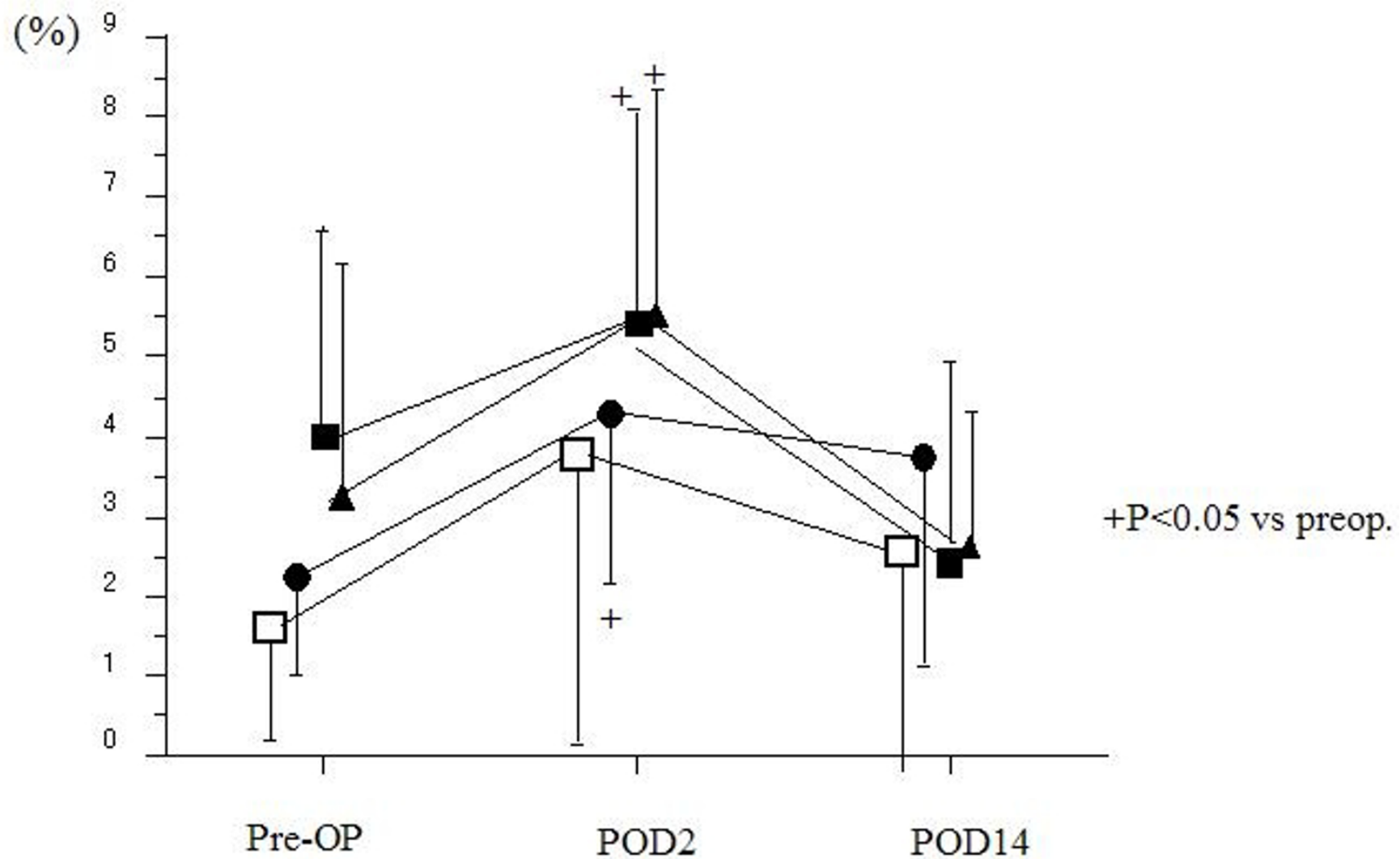

Figure 4

Perioperative changes of measurements of IL-4 in surgical patients. (Black squares - gastric resection $(\mathrm{n}=40)$, black circles - colorectal resection $(n=34)$, black triangles - hepatic resection $(n=20)$, white squares - laparoscopic cholecystectomy $(n=12)$ ). There were significant differences in the percentage of CD4+ IL-4+T cells between malignancy group and LC groups prior to surgery. The postoperative percentage of CD4+ IL-4+T cells in all groups significantly increased on POD 2 compared with before operation.

tumor cells infiltrate the lymph node, the generation of Th cells in the lymph node environment is shifted towards a Th2-type immune response. The ability of IL-4 to inhibit IL-2 gene transcription has been confirmed by other researchers $[14,15]$, suggesting that the elevation of IL-4 production during an ongoing immune response to tumor can down-regulate Th1 cytokine production. Therefore, in gastrointestinal cancer patients, the initial tumor establishment may arise from, or be accompanied by, a reduced Th1/Th2.

Hensler et al. [16]reported that during the early postoperative course, major surgery resulted in a severe defect of $\mathrm{T}$ cells to proliferate and to secrete cytokines characteristic of both Th1 and Th2 phenotypes. They also reported that during the late postoperative course (day 5), production of IL- 2 and IFN- $\gamma$ had increased, reaching levels similar to those observed before surgery. O'Sullivan et al., [14] demonstrated that peripheral blood mononuclear cells from trauma patients examined 1 to 14 days after injury produced significantly less IFN- $\gamma$ than those from healthy control subjects, but production of IL-4 was increased. With respect to lymphocyte numbers, we found that lymphocyte numbers were depressed on POD 2 after major surgery, and recovered within the first postoperative week. Both the reduction in lymphocyte numbers and their subsequent recovery varied with the extent of surgical procedure. Some studies have found decreases in both CD4+ and CD8+ lymphocytes following major surgery [17], while other studies on gastric cancer patients revealed a significant decrease in numbers of CD8+ but not CD4+ lymphocytes [18] although our study only investigated bulk lymphocyte numbers.

The present findings showed that the Th1/Th2 balance in the LC group as well as malignancy group decreased on POD 2, but the decrease in the LC group was slight on POD 2. The increase percentage of CD4+IL-4+ T cells in all 


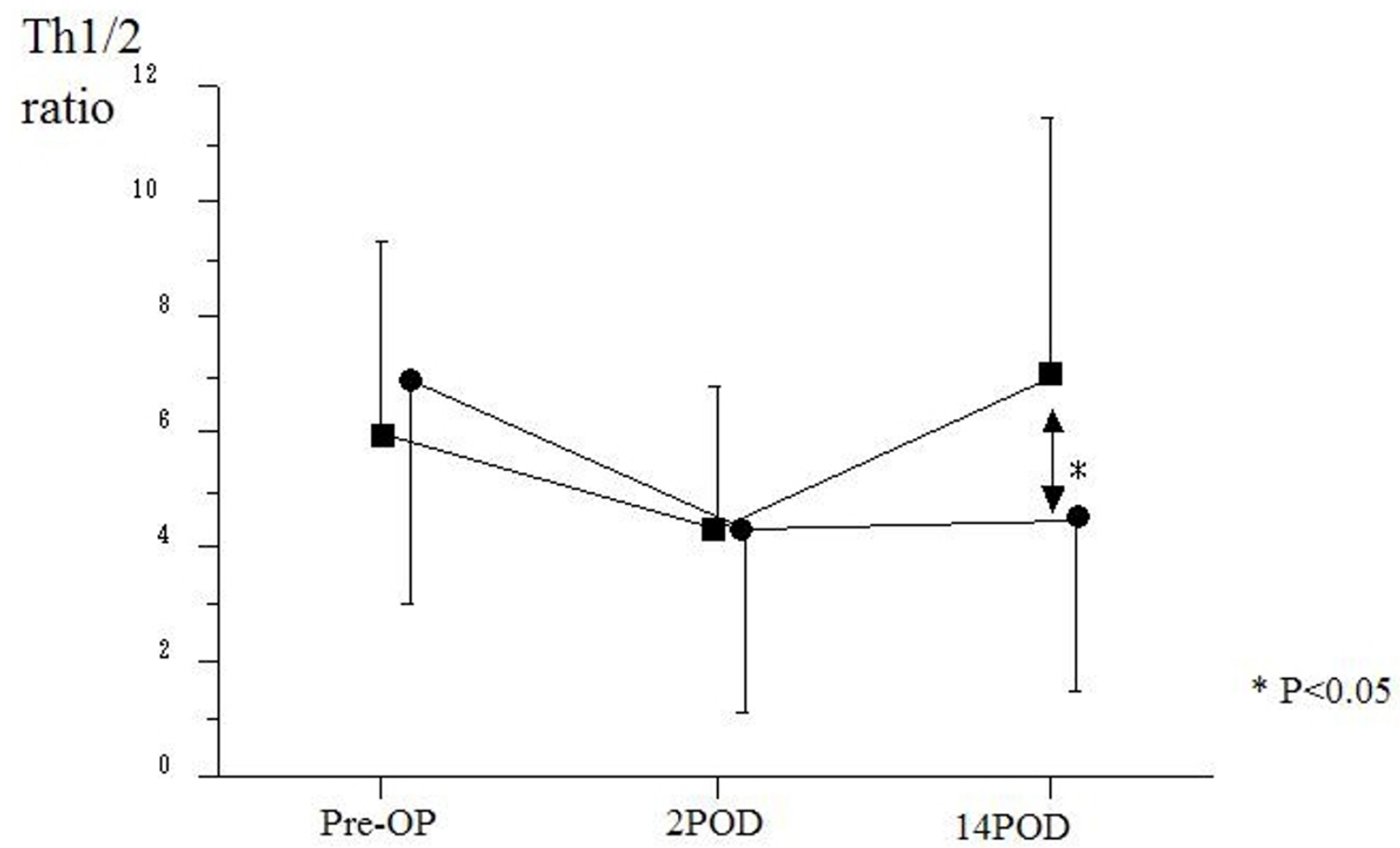

\section{Figure 5}

Changes in ThI/Th2 ratio in surgical patients with malignancy from the viewpoint of postoperative complications. (Complication $(-) n=84$, complication $(+) n=10$ ) The patients with postoperative complications showed significantly lower ThI/2 ratios on POD I 4 although there were no significant differences in the two groups before operation or on POD 2.

groups resulted in the observed decrease in the Th1/Th2 ratios. Interestingly, there were no significant differences on POD 14 among all groups corresponding with the finding of O'Sullivan et al [14].

Two important questions remain to be answered; whether a shift in the Th1/Th2 balance can be used to facilitate comparisons of different surgical procedures, and the clinical significance of the surgery-induced shift in the Th1/ Th2 balance. The present findings confirm the findings of Decker et al., [10] who demonstrated that the Th1/Th2 balance illustrated by the IL-4/IFN- $\gamma$ and CD23/HLA-DR ratios was markedly different between LC and open cholecystectomy. It was shown that down-regulation of the Th1 immune response makes patients more susceptible to infections with viruses and intracellular bacteria. However, no study has examined to what extent operative procedures in major abdominal surgeries influence the Th1/ Th2 balance. To our knowledge, the present study is one of the first to provide information on the Th1/Th2 ratio during the early and delayed period after different major abdominal surgeries from a rather large patient sample. The Th1/Th2 balance in patients undergoing hepatic resection decreased significantly as compared with those in gastric resection and colorectal resection on POD 2 but a significant difference was not noted between the three groups preoperatively or later in the postoperative course (POD 14).

The present study also showed that a shift toward a Th2 immune response continued until POD 14 in patients who developed postoperative complications. There was no significant difference in the preoperative and POD 2 Th1/Th2 balance, regardless of the presence of postoperative complications. The first clinical signs of major postoperative complications were invariably preceded by a significant decline in Th1/Th2 balance after major abdominal surgeries. Therefore, these data support a causative relationship between the post-operative severity of immunosuppressive sequelae and the patient's susceptibility to infectious complications. However, it is difficult to predict the occurrence of postoperative complications 
from the ratio of the Th1/Th2 balance in patients prior to operation $[19,20]$. Post-surgical immunosuppression may be favored by the preoperative clinical-biological status of patients and the extent of surgical trauma such as hormonal changes evoked by stress, hemorrhage, transfusion and duration of the operation. In the present study, the patient's Th1/Th2 ratio before surgery or on POD 2 was not an associated factor in predicting postoperative complications, but the percentage of CD4+IL- $4+\mathrm{T}$ cells in patients with postoperative complications was significantly higher than in patients without complications. Therefore, the increased percentage of Th2 cells may predict the occurrence of postoperative complications. On the other hand, van Sandick et al. [17], demonstrated that preoperative IFN- $\gamma$ production acted as an independent predictive variable for the occurrence of postoperative major infection. Davis et al. [20], recently reported on the possible role of the IFN- $\gamma$ receptor 1 gene in predicting major infection after operations. As severe trauma such as hepatic resection and occurrence of postoperative complications were associated with decreased numbers of IFN- $\gamma$ producing $\mathrm{T}$ cells, a deficiency in the type 1 response may play a key role in immune suppression of such patients, as reported in this study $[9,21]$.

\section{Conclusion}

The present study has demonstrated that the elevation of Th2 subset in patients with stage I cancer as compared with healthy subjects or patients with cholecystolithiasis suggests that the tumor-bearing state may induce a switch from a Th1-type to a Th2-type cytokine profile, although further research is necessary. Although there is an increase in the representation of Th2 cells among CD4+ peripheral lymphocytes in patients with gastrointestinal cancer, there is no corresponding decrease in the frequency of Th1 cells.

Impaired host immunity or excessive stress after major surgery often increases susceptibility to infection. These results suggest that the extent of postoperative immune depression is related to the extent of surgical tissue resection. The determination of Th1/Th2 balance may be of help in evaluating different surgical procedures and properly monitoring patients post-surgery.

\section{Competing interests}

The authors declare that they have no competing interests.

\section{Authors' contributions}

MI was involved in the design of the study and writing of the manuscript. $\mathrm{MN}$ and $\mathrm{NH}$ assembled the data. TM and YK performed the statistical analysis. HI and HK performed the study of flowcytometry. YN designed the study. All authors read and approved the final manuscript.

\section{References}

I. Sato M, Goto S, Kaneko R, Ito M, Sato S, Takeuchi S: Impaired production of Thl cytokines and increased frequency of Th2 subsets in PBMC from advanced cancer patients. Anticancer Res 1998, 18:395।-3955.

2. Mosmann TR, Coffman RL: Th I and Th 2 cells: Different patterns of lymphokine secretion lead to different functional properties. Ann Rev Immunol 1989, 7:145-173.

3. Mosmann TR, Cherwinski H, Bond MW, Giedlin MA, Coffman RL: Two types of murine helper $\mathbf{T}$ cell clone. J Immunol 1986, 36:2348-2357.

4. Pellegrini P, Berghella AM, Del Beato T, Cicia S, Adorno D, Casciani $\mathrm{CU}$ : Distribution in ThI and Th2 subsets of CD4+T cells in peripheral blood of colorectal cancer patients and involvement in cancer establishment and progression. Cancer Immunol Immunother 1996, 42: I-8.

5. Elsasser-Beile U, Kolble N, Grussenmeyer T, Schultze-Seemann W, Wetterauer U, Gallati H, Schulte Mönting J, von Kleist S: ThI and Th2 cytokine response patterns in leukocyte cultures of patients with urinary bladder, renal cell and prostate carcinomas. Tumor Biol 1998, 9:470-476.

6. Ishikawa M, Nishioka M, Hanakiet N, Miyauchi T, Kashiwagi Y, Miki H Hepatic resection leads to a shift in the $T h I / 2$ balance toward Th2 and produces hypermetabolic and heperhemodynamic states. Hepato-gastroenterology 2004, 5 I: I 422-I 427.

7. Berguer R, Bravo N, Bowyer M, Egan C, Knolmayer T, Ferrick D: Major surgery suppresses maximal production of helper $T$. cell type I cytokines without potentiating the release of helper T-cell type 2 cytokines. Arch Surg 1999, 134:540-544.

8. Goto S, Sato M, Kaneko R, Itoh M, Sato S, Takeuchi S: Analysis of Th $I$ and Th 2 cytokine production by peripheral blood mononuclear cells as a parameter of immunological dysfunction in advanced cancer patients. Cancer Immunol 1999, 48:435-442.

9. Cras $A E$, Galley HF, Webster N: Spinal but not anesthesia increases the ratio of $\mathrm{T}$ helper $\mathrm{I}$ to $\mathrm{T}$ helper 2 cell subsets in patients undergoing transurethral resection of the prostate. Anesth Analg 1998, 87: | 421-1425.

10. Ishikawa M, Nishioka M, Hanaki N, Miyauchi T, Kashiwagi Y, Miki H: Hepatic resection leads to predominance of the T-helper-2 lymphocyte phenotype. Hepatology research 2004, 30:96-103.

II. Decker D, Schondorf M, Bidlingmaier F, Hirner A, von Ruecker AA: Surgical stress induces a shift in the type-1/type-2 T-helper cell balance, suggesting down-regulation of cell-mediated immunity commensurate to the trauma. Surgery 1996, I 1 9:316-325

12. Openshaw P, Murphy EE, Hosken NA, Maino V, Davis K, Murphy K, $O$ 'Garra A: Heterogenecity of intracellular cytokine synthesis at the single-cell level in polarized $T$ helper $I$ and $T$ helper 2 populations. J Exp Med 1995, 182:1357-1367.

13. Nakazato H, Koike A, Saji S, Ogawa N, Sakamoto J: Efficacy of immunochemotherapy as aduvant treatment after curative resection of gastric cancer. Lancet 1994, 343: I I 22- I I 26.

14. O'Sullivan ST, Lederer JA, Horgan AF, Chin DH, Mannick JA, Rodrick ML: Major injury leads to predominance of the $\mathbf{T}$ helper-2 lymphocyte phenotype and diminished interleukin- 12 production associated with decreased resistance to infection. Ann Surg 1995, 222:482-492.

15. Reynolds JV, Daly JM, Shou J, Sigal R, Ziegler MM, Naji A: Immunologic effects of arginine supplementation in tumor-bearing and non-tumor-bearing hosts. Ann Surg 1990, $211: 202-210$.

16. Hensler T, Hecker H, Heeg K, Heidecke CD, Bartels H, Barthlen W, Wagner $\mathrm{H}$, Siewert JR, Holzmann B: Distinct mechanisms of immunosuppression as a consequence of major surgery. Infect Immun 1997, 65:2283-2291.

17. van Sandick JW, Gisbertz SS, ten Berge IJ, Boermeester MA, Pouw Kraan TC van der, Out TA, Obertop H, van Lanschot JJ: Imuune responses and prediction of major infection in patients undergoing transhiatal or transthoracic esophagectomy for cancer. Ann Surg 2003, 237:35-43.

18. Barbieri C, Fujisawa MM, Yasuda CL, Metze IL, Oliveira EC, Santos LM, Lopes LR, Andreollo NA: Effect of surgical treatment on the cellular immune response of gastric cancer patients. Braz J Biol Res 2003, 36:339-345.

19. Tatsumi H, Ura H, Ikeda S, Yamaguchi K, Katsuramaki T, Asai $Y$, Hirata K: Surgical influence on ThI/Th2 balance and mono- 
cyte surface antigen expression and its relation to infectious complication. World J Surg 2003, 7:522-528.

20. Davis EG, Eichenberger MR, Grant BS: Microsatellite maker of interferon-gamma receptor I gene correlates with infection following major trauma. Surgery 2000, I 28:30I-305.

21. Ishikawa M, Nishioka M, Hanaki N, Miyauchi T, Kashiwagi Y, Kawasaki Y, Miki H, Kagawa H, loki H, Nakamura Y: Postoperative host responses in elderly patients after gastrointestinal surgery. Hepatogastroenterology 2006, 53:730-735.

Publish with Biomed Central and every scientist can read your work free of charge

"BioMed Central will be the most significant development for disseminating the results of biomedical research in our lifetime. " Sir Paul Nurse, Cancer Research UK

Your research papers will be:

- available free of charge to the entire biomedical community

- peer reviewed and published immediately upon acceptance

- cited in PubMed and archived on PubMed Central

- yours - you keep the copyright

Submit your manuscript here:

http://www.biomedcentral.com/info/publishing_adv.asp 